remarkable qualities: sailor, cellist, and so on, and includes "communist", without explanation. This is a reprehensible distortion. Monod joined the French communist party during the war for just one reason, he told me: it was the only way he could have any influence on the strategy and tactics of the armed resistance, in which he then rose to chief of operations for all of France. After the war he quietly dropped out, until in 1948 he publicly denounced the fraudulent claims of Stalin's geneticist and science chief, Trofim Lysenko - and with terrific effect.

Horace Freeland Jud son is at 807 West

University Parkway, Baltimore,

Maryland 21210, USA.

\title{
Coping with uncertainty
}

\section{From Cosmosto Chaos: The Science of Unpredictability \\ by Peter Coles \\ Oxford University Press: 2006. 224 pp. \\ $£ 25, \$ 44.50$}

\section{Gianpietro Malescio}

If the process through which civilization evolved were condensed into a few words, these could be: posing questions, finding answers. As those with children know well, wondering about the world is intrinsic to human nature. This attitude is generally lost as we grow up (life is a tough business), but a good scientist retains it as an adult. In principle, finding answers is the ultimate goal of a scientist. However, scientific answers have a peculiar character: they do not represent absolute truth acquired once and for all, but only temporary beliefs subject to continuous, critical revision. Scientific knowledge is anti-dogmatic: it represents the most reliable conclusion that can be drawn on the basis of the available data. There are no certainties in the realm of science. This may seem profoundly disappointing to the general public, but it should not. Science is a way of thinking much more than it is a body of knowledge. Its true achievement is not providing answers, but rather a method through which answers can be sought.

A basic instrument of this method is represented by probability theory. As Peter Coles brilliantly illustrates in his engaging new book, From Cosmos to Chaos, probability theory makes it possible to extract meaningful information from a sea of noisy data, to deal with intrinsically probabilistic processes, and to infer conclusions on the basis of incomplete information.

After explaining the basics of probability theory, Coles offers a ride across virtually the entire spectrum of the physical sciences, including thermodynamics, cosmology, chaos theory and quantum mechanics, as well as stimulating issues such as the anthropic principle and life on other worlds. Each topic is considered from the specific perspective of how it involves, and is related to, the concept of probability. Coles also examines the impact of probability on many aspects of everydaylife. He shows us how the decisions of law courts and medical tests, as well as more mundane activities such as gambling strategies, may suffer deeply from an incorrect use of statistics. To illustrate how probability theory works, Coles presents some intriguing and often surprising examples, encouraging readers to think for themselves and providing them with material to entertain and amaze their friends. I particularly appreciated the historical notes and lively anecdotes that highlight the famous and less well-known personalities who contributed to the development of the statistical of the bayesian approach. Pragmatically, the two interpretations should be considered as complementary, rather than competing. Undoubtedly, bayesian inference has profound implications as it concerns critical thinking and may lead to a deeper understanding of the scientific method. However, the ability to develop a new hypothesis or theory relies in the end on scientists' creativity, something that can hardly be delimited within a methodological framework.

I have a minor observation. Randomness, which is intrinsically related to probability, deserves a more detailed discussion than is given here. In particular, the Monte Carlo method is mentioned only briefly, despite its importance and wide use in virtually every branch of science.

Altogether, the book provides a truly enjoyable overview of the role of probability in science, as well as in everyday life. It is aimed essentially at non-specialist readers, but even those who are familiar with its contents will enjoy the stimulating presentation. Finally,

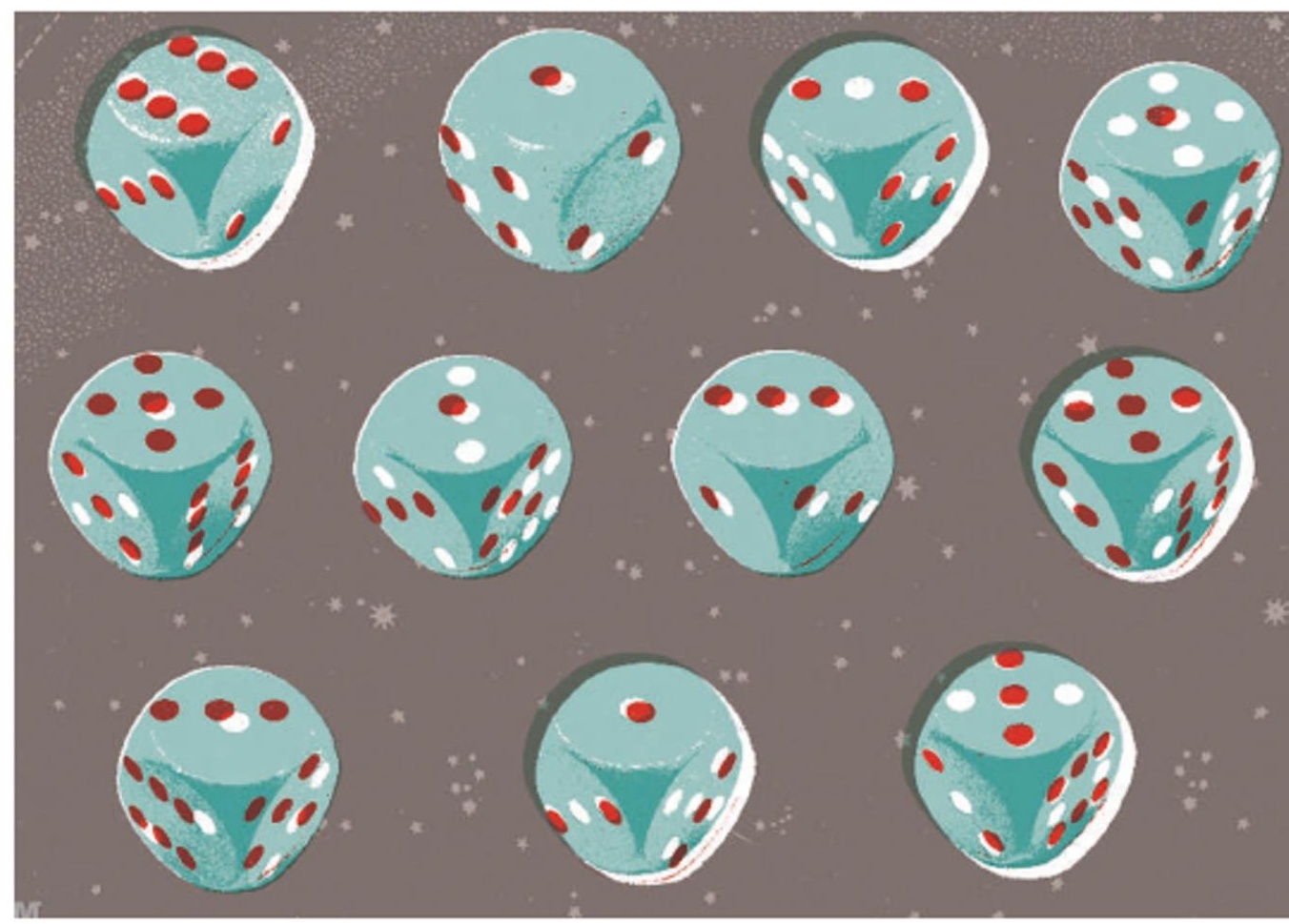

approach to science. Coles points out that most of these were astronomers. Historically, men of science generally applied their talents to a range of disciplines, so most of the people cited in the book might also be considered as mathematicians and physicists.

A central chapter of the book is devoted to the controversy between the frequentist and the bayesian interpretations of probability. The former interprets probability as a frequency of occurrence in repeated experiments, whereas in the latter probability measures the degree of belief an individual has in an uncertain proposition. As Coles openly declares, one of the book's objectives is to argue in favour
I fully endorse Coles' passionate plea at the end of the book for a better integration of science and society. To face challenges such as large-scale pollution, the energy crisis or food shortages, we will need all the instruments that science puts at our disposal. Perhaps an even greater threat is represented by fundamentalisms of any kind (religious, political, economical) that aim to impose their dogmas on the whole of society. Science, or rather, the forma mentis it gives us, may offer the best antidote for defying them.

Gianpietro Malescio is in the Department of

Physics, University of Messina,

98166 Messina, Italy. 